\title{
Investigação Teórica de Adições Aldólicas de Monocarbonilas e $\beta$-Dicarbonilas Catalisadas
}

\author{
Ellen V. D’Alessandro \& Josefredo R. Pliego Jr.
}

\section{Introduction}

As reações aldólicas são conhecidas há mais de um século e estão entre as mais úteis em química orgânica, sendo um tópico clássico. ${ }^{1}$ Parte de sua importância reside na habilidade de formação de ligações carbonocarbono (Esquema 1).

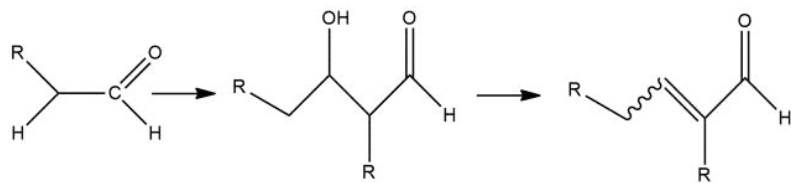

Esquema 1. Adição e condensação aldólica.

A reação pode ser via catálise ácida ou básica. Também pode ocorrer catálise via formação de enamina, um mecanismo de grande interesse em organocatálise. Apesar do tempo que esta reação é conhecida, e dos vários estudos teóricos e experimentais já realizados, ainda existem muitos aspectos não bem esclarecidos desta reação. ${ }^{2}$ Soma-se a isso o fato de que muitos estudos abordam aspectos específicos, faltando uma visão mais ampla da reação em todas suas etapas. Baseado nestas considerações, iniciamos estudos teóricos/ computacionais desta classe de reações com o objetivo de montar o perfil de energia livre global, analisando os vários equilíbrios, etapas de ativação (estados de transição), e efeito do solvente.

Neste trabalho, abordaremos a catálise básica com piperidina em metanol como solvente. Como sistemas modelo, estudamos a reação de acetona com benzaldeído, que é uma reação aldólica clássica. Estudamos também a reação aldólica envolvendo um composto betadicarbonílico, a aceto-acetona, mais ativado em relação a desprotonação, com o benzaldeído. Esta última reação recebe o nome de Knoevenagel. A etapa estudada até o momento é a adição aldólica, que consiste da formação do ceto-álcool.

\section{Metodologia}

Otimização de geometria para obter os mínimos e estados de transição foram realizados em nível CPCM/X3LYP/6-31(+)G(d), de forma a incluir o solvente na otimização de geometria. Este nível de teoria foi utilizado também para realizar o cálculo de frequências harmônicas, de forma obter a energia livre em fase gasosa. Uma vez obtido os pontos estacionários, realizamos cálculos da energia em nível M08-HX com bases TZVPP aumentadas com funções difusas sp sobre o oxigênio e nitrogênio. Por fim, a energia livre de solvatação foi calculada em nível SMD, com densidade X3LYP/6-31(+)G(d). 


\section{Resultados e Discussões}

O trabalho envolveu duas reações: (a) acetona com benzaldeído e (b) aceto-acetona com benzaldeído, ambas catalisadas pela piperidina, atuando como catalisador básico.

No primeiro sistema investigado, acetona mais benzaldeído, a primeira etapa da reação é a desprotonação da acetona pela piperidina, formando um enolato (MS1). Para calcular a energia livre deste processo, utilizamos a reação de troca de próton da acetona com fenóxido (pka de 14,0 em metanol) e determinamos que o pKa da acetona é 25,0 em metanol. Com base neste valor e no $\mathrm{pKa}$ da piperidina protonada $(11,7)$, a primeira etapa de reação tem uma energia livre de 19,2 kcal/mol, como mostrado no diagrama da Figura 1. Na etapa seguinte, o enolato formado atua como um nucleófilo e ataca o benzaldeído via um estado de transição TS1, formando o intermediário MS2. A barreira de energia livre para esta etapa é de $16,1 \mathrm{kcal} / \mathrm{mol}$, que somada a etapa anterior, leva a uma barreira global de $35,3 \mathrm{kcal} / \mathrm{mol}$. $\mathrm{O}$ intermediário formado, MS2, é essencialmente um alcóxido, que pode pegar um próton do meio e gerar o produto final MS3, um ceto-álcool. Como podemos notar, a piperidina não é uma base forte o suficiente para desprotonar favoravelmente a acetona, tornando o mecanismo inviável com esta base.

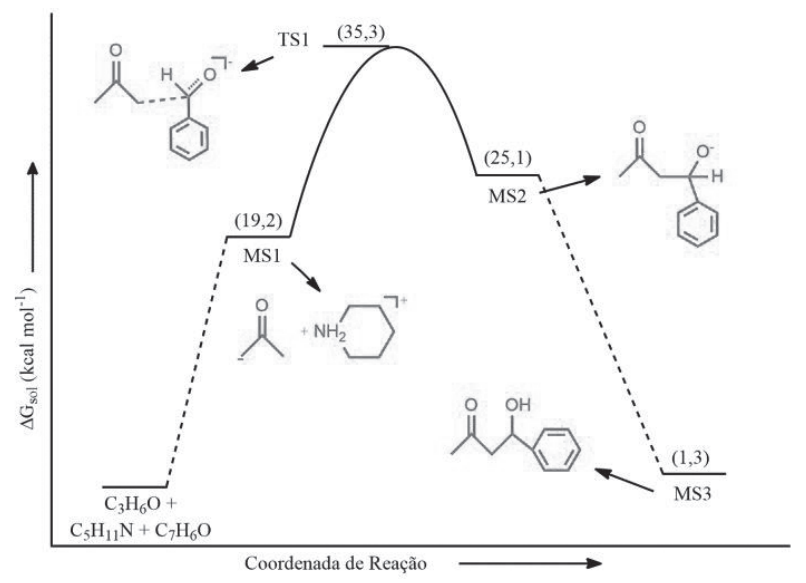

Figura 1. Diagrama de energia livre para a reação de acetona com benzaldeído.
Na segunda reação, envolvendo a aceto-acetona, a etapa de desprotonação é muito favorável, com uma energia livre de apenas $0,8 \mathrm{kcal} / \mathrm{mol}$ (Figura 2). Na etapa de ataque do enolato ao benzaldeído, a barreira é mais alta do que a anterior, 21,0 kcal/ mol. Isto se deve ao maior impedimento espacial da aceto-acetona desprotonada. A barreira final de 21,8 $\mathrm{kcal} / \mathrm{mol}$ torna este mecanismo viável, apesar do valor levemente positivo da energia livre do produto final de 2,6 kcal $/ \mathrm{mol}$.

Há na literatura alguns dados de substratos parecidos que podemos comparar valores cinéticos. Medien reportou a cinética da reação de ácido de Meldrum com benzaldeído em DMSO a temperatura ambiente. ${ }^{3}$ Com base em seus dados, podemos estimar uma barreira de energia livre de 19,7 kcal/ mol. Rodriguez et al. ${ }^{4}$ utilizaram esponja de próton como catalisador da reação de acetoacetato de etila com benzaldeido em DMSO a 80 oC, e seus dados de conversão nos permite estimar uma barreira de 28 $\mathrm{kcal} / \mathrm{mol}$. A temperatura mais alta eleva a energia livre, de modo que um valor de $26 \mathrm{kcal} / \mathrm{mol}$ seria razoável a 25 oC. Estas comparações indicam que a barreira obtida neste trabalho está dentro da faixa de valores experimentais.

\section{Conclusões}

Os altos valores de $\Delta$ Gsolł na reação (a) mostram o quanto é desfavorável esta reação via catálise com

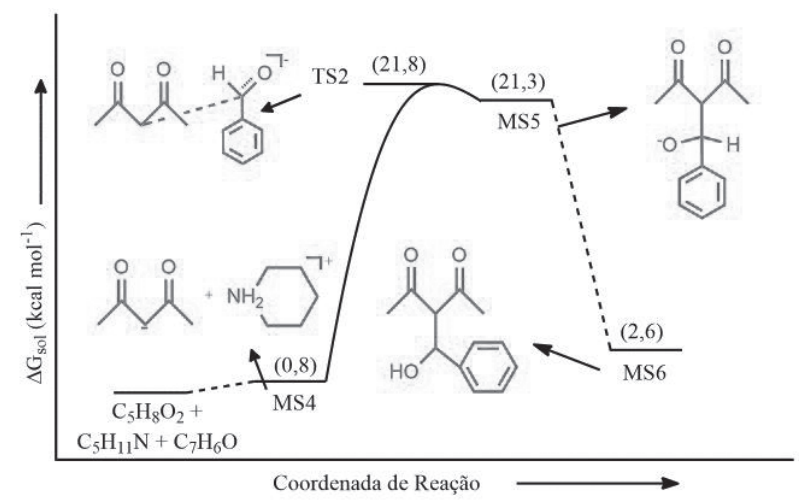

Figura 1. Diagrama de energia livre para a reação de acetona com benzaldeído. 
piperidina. Seria necessário metóxido $(\mathrm{pKa}(\mathrm{CH} 3 \mathrm{OH})=$ 18,3) para desprotonar a acetona em metanol numa extensão apreciável. Já a reação (b), de Knoevenagel, a acetoacetona é bem mais facilmente desprotonada, e a reação seria observada, mesmo que a etapa de adição tenha uma barreira maior devido a repulsão espacial. Os resultados obtidos estão em concordância com as observações experimentais para ambos os sistemas.

\section{Agradecimentos}

Os autores agradecem ao suporte das agências CNPQ e FAPEMIG

\section{Referências}

1. Carey, F.; Sundberg, R. J., Advanced Organic Chemistry. Part B: Reactions and Synthesis. 4 ed.; Kluwer Academic/ Plenum Publishers: New York, 2000;

2. Zhang, X.; Houk, K. N., Acid/Base Catalysis by Pure Water: The Aldol Reaction. J. Org. Chem. 2005, 70, 9712-9716;

3. Medien, H. A. A., Kinetic Studies of Condensation of Aromatic Aldehydes with Meldrum's Acid. Zeitschrift für Naturforschung B 2002, 57, 1320-1326;

4. Rodriguez, I.; Sastre, G.; Corma, A.; Iborra, S., Catalytic Activity of Proton Sponge: Application to Knoevenagel Condensation Reactions. J Catal 1999, 183, 14-23.

\section{Ellen V. D'Alessandro* \& Josefredo R. Pliego Jr.}

Departamento de Ciências Naturais, Universidade Federal de São João del Rei

*E-mail: dalessandroellen@gmail.com 